\title{
CHARGE CARRIER MOBILITY FLUCTUATIONS DUE TO THE CAPTURE-EMISSION PROCESS
}

\author{
V. Palenskis, J. Vyšniauskas, J. Glemža, and J. Matukas \\ Institute of Applied Electrodynamics and Telecommunications, Vilnius University, Sauletekio 3, 10222 Vilnius, Lithuania \\ Email: vilius.palenskis@ff.vu.lt
}

Received 6 December 2017; revised 26 January 2018; accepted 21 June 2018

\begin{abstract}
It is shown that the free charge carrier capture-emission process causes both the charge carrier density and mobility fluctuations. In this report we present the calculation results in order to find how the capture-emission process affects the free charge carrier mobility and mobility fluctuations. The carrier mobility dependence on phonon, impurity and carrier-carrier scatterings, and the mobility dependence on the electric field and the energy gap variation due to the doping level were taken into account. It is also shown that fluctuations of the charge carrier density and mobility due to the capture-emission process are completely correlated, and that their relaxation times are the same as for the charge capture-emission process. The general expression for estimation of active capture centre density in the volume of a homogeneous sample from the low-frequency noise measurements is presented.
\end{abstract}

Keywords: low-frequency noise, charge carrier number and mobility fluctuations, defects, RTS, Lorentzian spectrum

PACS: $05.40 . \mathrm{Ca}, 07.50 . \mathrm{Hp}, 71.55 .-\mathrm{i}, 72.70+\mathrm{m}$

\section{Introduction}

Although investigations of the nature of flicker $(1 / f)$ noise have old traditions and deep roots going back many decades, the origin of the $1 / f$ noise is still subject to discussions. There are two main opposite points on the origin of $1 / f$ noise: (i) the observed $1 / f$ noise is due to the charge carrier capture-emission in traps of defects [1]7], (ii) the observed $1 / f$ noise is caused by fluctuations in mobility of the free charge carriers in the conducting material due to charge carrier lattice (phonon) scattering [8 14$]$.

An analysis of physical mechanisms of the lowfrequency noise in homogeneous materials, presented in papers [15, 16, shows that a vision on proportionality of the resistance fluctuation spectral density to the inverse number of the free charge carriers can be explained only as an inverse proportionality to the sample volume because the ratio be- tween the numbers of defects and free electrons in the investigated homogeneous samples hardly depends on the volume at all. The minimum number of active defects (relaxators) with relaxation times distributed in a wide time range needed for generating the $1 / f$ noise law in a given frequency range has also been estimated, and this requirement is fulfilled when the relaxation times are arbitrarily distributed one-by-one in every two-octave range. The profile of the $1 / f$ spectrum does not depend on the volume of the sample: the volume only determines the intensity of the $1 / f$ noise. When the number of relaxators of a particular type with particular relaxation times is many times greater than the average number of relaxators with other relaxation times, one can observe the Lorentzian type spectrum over $1 / f$ noise. The presented analysis shows that the charge carrier capture and emission process is the main source for generating $1 / f$ noise and 
random telegraph signal (RTS) noise [15, 16]. It was also shown that for some homogeneous semiconductors in a particular doping range the charge carrier density $n$ gives such proportionality for the mobility $\mu: \mu^{2} \sim 1 / n$. As a result, the $1 / f$ noise level increases as $\mu^{2}$, which was explained as mobility fluctuations [8-14] due to lattice scattering.

In this work we present the calculation data in order to show how the capture-emission process also causes the free charge carrier mobility fluctuations.

\section{A simulation model and parameters}

The calculation results of a silicon sample with dimensions of $5 \mu \mathrm{m} \times 5 \mu \mathrm{m} \times 1 \mu \mathrm{m}$ at lattice temperature $T=300 \mathrm{~K}$ and at a small constant applied bias voltage (linear regime) will be presented. The calculations have been performed by using a drift-diffusion model based on the Poisson's equation for electrostatic potential and the continuity equations for electrons and holes according to the Synopsis TCAD Sentaurus program, in order to find how the capture-emission process affects not only the free charge carrier number fluctuations but also the charge carrier mobility fluctuations. In these calculations the carrier mobility dependence on phonon, impurity and carrier-carrier scatterings, mobility dependence on the electric field and the energy gap variation due to the doping level were also taken into account.

Low field charge carrier mobility $\mu_{\text {low }}$ was calculated using the Matthiessen's rule

$$
\frac{1}{\mu_{\mathrm{low}}}=\frac{1}{\mu_{\mathrm{dop}}}+\frac{1}{\mu_{\mathrm{cc}}}
$$

where $\mu_{\text {dop }}$ is the mobility due to scattering on ionized impurities [17], $\mu_{\mathrm{cc}}$ is the mobility due to carrier-carrier scattering (Brooks-Herring model [18]).

$$
\begin{aligned}
& \mu_{\mathrm{dop}}=\mu_{\mathrm{m}_{1}} \exp \left(-p_{\mathrm{c}} /\left(n_{\mathrm{a}}+n_{\mathrm{d}}\right)\right)+\left(\mu_{0}-\mu_{\mathrm{m}_{2}}\right) / \\
& {\left[1+\left(n_{\mathrm{a}}+n_{\mathrm{d}}\right) / C_{\mathrm{r}}\right]^{\alpha}-\mu_{1} /\left[C_{\mathrm{s}} /\left(n_{\mathrm{a}}+n_{\mathrm{d}}\right)\right]^{\beta},}
\end{aligned}
$$

where $\mu_{\mathrm{m}_{1}}=\mu_{\mathrm{m}_{2}}=52.2 \mathrm{~cm}^{2} / \mathrm{Vs}, \mu_{1}=43.4 \mathrm{~cm}^{2} /$ Vs, $p_{\mathrm{c}}=0, C_{\mathrm{r}}=9.68 \cdot 10^{16} \mathrm{~cm}^{-3}, C_{\mathrm{s}}=3.43 \cdot 10^{20} \mathrm{~cm}^{-3}$, $\alpha=0.68, \beta=2.0$ for electrons, and $\mu_{\mathrm{m}_{1}}=44.9 \mathrm{~cm}^{2} /$ Vs, $\mu_{\mathrm{m}_{2}}=0, \mu_{1}=29.0 \mathrm{~cm}^{2} / \mathrm{Vs}, p_{\mathrm{c}}=9.23 \cdot 10^{16} \mathrm{~cm}^{-3}$, $C_{\mathrm{r}}=2.23 \cdot 10^{17} \mathrm{~cm}^{-3}, C_{\mathrm{s}}=6.10 \cdot 10^{20} \mathrm{~cm}^{-3}, \alpha=0.719$, $\beta=2.0$ for holes, $n_{\mathrm{a}}$ and $n_{\mathrm{d}}$ are the acceptor and donor density, respectively. Mobility $\mu_{0}$ is only due to phonon scattering and, therefore, it is dependent only on the lattice temperature $T$,

$$
\mu_{0}=\mu_{\mathrm{L}}\left(T / T_{0}\right)^{-\gamma},
$$

where, $\mu_{\mathrm{L}}=1417 \mathrm{~cm}^{2} / \mathrm{Vs}, \gamma=2.5$ for electrons, and $\mu_{\mathrm{L}}=470.5 \mathrm{~cm}^{2} / \mathrm{Vs}, \gamma=2.0$ for holes, $T_{0}=300 \mathrm{~K}$.

$$
\begin{aligned}
& \mu_{\mathrm{cc}}=\frac{c_{1}\left(T / T_{0}\right)^{3 / 2}}{\phi\left(\eta_{0}\right) \sqrt{n p}}, \\
& \phi\left(\eta_{0}\right)=\ln \left(1+\eta_{0}\right)-\eta_{0} /\left(1+\eta_{0}\right), \\
& \eta_{0}(T)=\frac{c_{2}}{N_{\mathrm{c}} F_{-1 / 2}\left(n / N_{\mathrm{c}}\right)+N_{\mathrm{v}} F_{-1 / 2}\left(p / N_{\mathrm{v}}\right)}\left(T / T_{0}\right)^{2} .
\end{aligned}
$$

Here $c_{1}=1.56 \cdot 10^{21} \mathrm{~cm}^{-1} \mathrm{~V}^{-1} \mathrm{~s}^{-1}, c_{2}=7.63 \cdot 10^{19} \mathrm{~cm}^{-3}$, $n$ is the density of electrons, $p$ is the density of holes, effective density-of-states $N_{\mathrm{c}}=2.89 \cdot 10^{19} \mathrm{~cm}^{-3}$, $N_{\mathrm{v}}=1.819 \cdot 10^{19} \mathrm{~cm}^{-3}, F_{-1 / 2}$ is the Fermi integral.

For the calculation of charge carrier mobility $\mu$ dependence on the electric field $E$ the Canali model [19] was used:

$$
\mu(E)=\frac{\mu_{\text {low }}}{\left(1+\left(\mu_{\text {low }} E / v\right)^{b}\right)^{1 / b}} .
$$

Here $v_{\text {sat }}$ denotes the carrier saturation velocity equal to $1.07 \cdot 10^{7} \mathrm{~cm} / \mathrm{s}$ for electrons and $8.37 \cdot 10^{6} \mathrm{~cm} / \mathrm{s}$ for holes, $b=1.109$ for electrons and $b=1.213$ for holes.

Energy gap narrowing $\Delta E_{\mathrm{g}}$ dependence on the doping level was calculated using the Slotboom model [20],

$$
\begin{aligned}
& \Delta E_{\mathrm{g}}=E_{\text {ref }}\left[\ln \left(\left(n_{\mathrm{a}}+n_{\mathrm{d}}\right) / n_{\text {ref }}\right)\right. \\
& \left.+\left(\ln \left(\left(n_{\mathrm{a}}+n_{\mathrm{d}}\right) / n_{\text {ref }}\right)\right)^{2}\right]^{1 / 2},
\end{aligned}
$$

where $E_{\text {ref }}=9.0 \cdot 10^{-3} \mathrm{eV}, n_{\mathrm{ref}}=10^{17} \mathrm{~cm}^{-3}$.

For modelling of electron capture-emission process one trap level at $0.4 \mathrm{eV}$ from the conduction band with a capture cross section equal to $10^{-14} \mathrm{~cm}^{2}$ was used. This trap is uncharged when unoccupied and carries the charge of one electron when it is occupied, i.e. the change of the density $\Delta n$ of free electrons is equal to the density of active traps $n_{\mathrm{tr}}=\Delta n$, and that reveals the appearance of the additional negative ion density equal to $\Delta n$. 


\section{Simulation results and discussion}

Now let us see what will happen with free charge carrier mobility in the case of the free charge carrier capture-emission process in traps. The number of filled and empty localized states of traps changes during the retrapping process, i.e. it changes the number of the ionized and neutral trap densities, which to a certain degree induce the changes of the average relaxation times for different scattering mechanisms and mobility: it depends on the material doping density, density of traps (defect states), impurities, and also on temperature. At first, we calculated the mobility $\mu_{1}$ of electrons without the capture of free electrons, and then obtained the mobility $\mu_{2}$ with the capture, and evaluated the change of the mobility $\Delta \mu=\mu_{1}-\mu_{2}$.

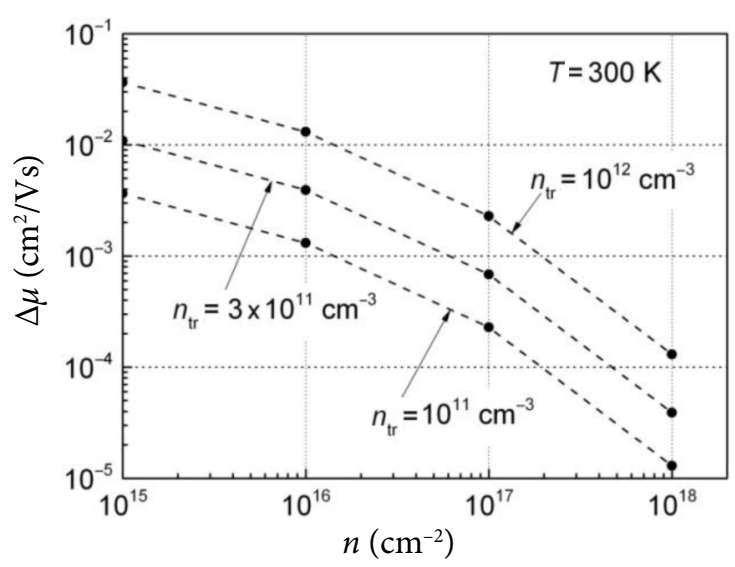

Fig. 1. Mobility magnitude change $\Delta \mu$ dependence on the free charge carrier density at three active trap densities $n_{\mathrm{tr}}, \mathrm{cm}^{-3}: 10^{11} ; 3 \cdot 10^{11} ; 10^{12}(T=300 \mathrm{~K})$.

Usually, in order to explain the conductivity fluctuations of homogeneous material, the conductivity $\sigma$ fluctuations due to both charge carrier density $n$ and their mobility $\mu$ fluctuations are presented in the following way:

$$
\frac{\Delta \sigma}{\sigma}=\frac{\Delta n}{n}+\frac{\Delta \mu}{\mu} .
$$

The change in mobility $\Delta \mu$ dependence on the free electron density $n$ at various active electron capture centre densities $n_{\text {tr }}$ is presented in Fig. 1. From Fig. 2 it is seen that for $n \gg \Delta n$ the change of the mobility $\Delta \mu$ is proportional to the captured density of electrons: $\Delta \mu=a \Delta n$ (here $a$ is the factor of proportionality). It gives that these quantities are

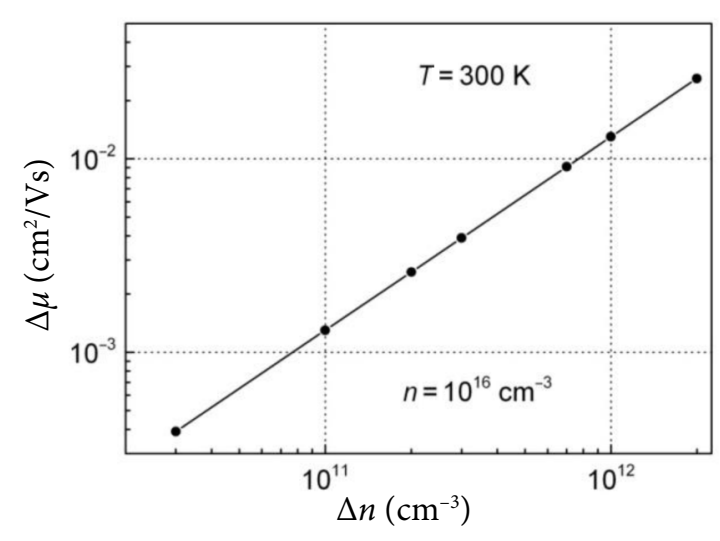

Fig. 2. The mobility change $\Delta \mu$ dependence on the captured free electron density $\Delta n$.

completely correlated, i.e. their correlation coefficient is equal to unity:

$$
\begin{aligned}
& r=\frac{\langle\Delta n \cdot \Delta \mu\rangle}{\left\langle(\Delta n)^{2}\right\rangle^{1 / 2} \cdot\left\langle(\Delta \mu)^{2}\right\rangle^{1 / 2}} \\
& =\frac{\langle\Delta n \cdot \alpha \Delta n\rangle}{\left\langle(\Delta n)^{2}\right\rangle^{1 / 2} \cdot\left\langle\alpha^{2}(\Delta n)^{2}\right\rangle^{1 / 2}}=\frac{\left.\alpha<(\Delta n)^{2}\right\rangle}{\left.\alpha<(\Delta n)^{2}\right\rangle}=1 .
\end{aligned}
$$

Here the quantity with brackets $<. .>$ means a statistical average.

The relative mobility change $\Delta \mu / \mu$ dependence on the free charge carrier density for different capture centre densities is shown in Fig. 3. At the given free charge carrier range the relative mobility variation is within the interval between $10^{-5}$ and $10^{-7}$. Comparison of mobility $\mu$, its absolute $(\Delta \mu)$ and relative $(\Delta \mu / \mu)$ change dependences on the free charge carrier density in the presence of the active trap density $n_{\mathrm{tr}}=3 \cdot 10^{11} \mathrm{~cm}^{-3}$ are presented in Fig. 4. The mobility $\mu$ calculation data agree with

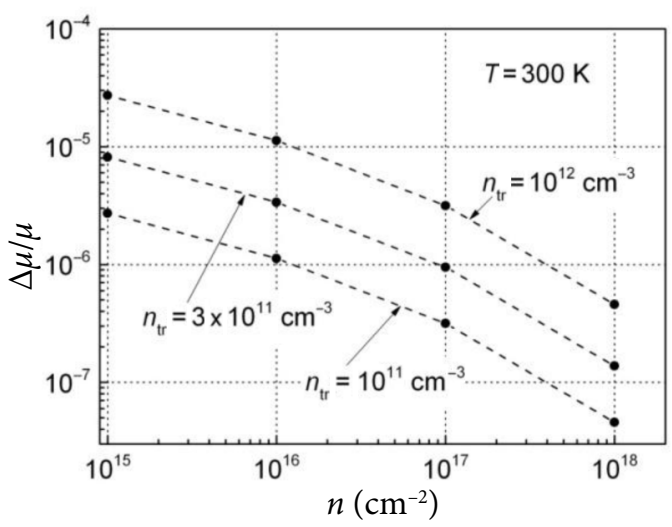

Fig. 3. Relative mobility change $\Delta \mu / \mu$ dependence on the free charge carrier density at three active trap densities $n_{\mathrm{tr}} \mathrm{cm}^{-3}: 10^{11} ; 3 \cdot 10^{11} ; 10^{12}(T=300 \mathrm{~K})$. 


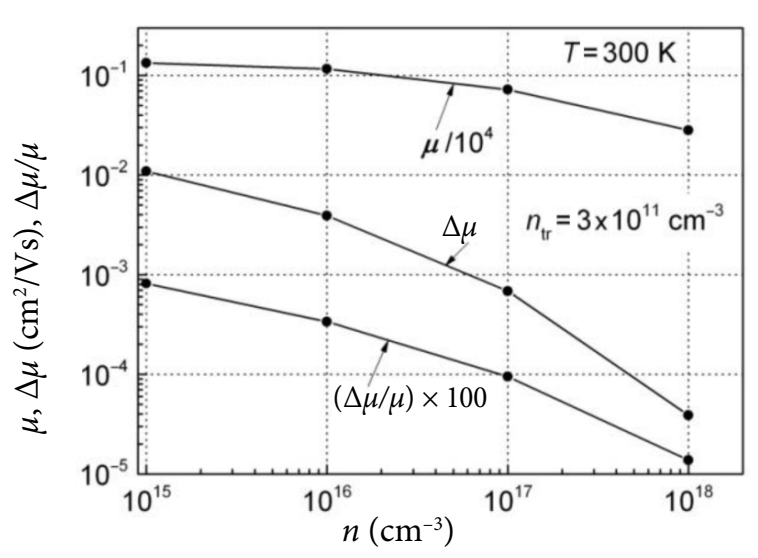

Fig. 4. Comparison of the mobility and dependences of its absolute $(\Delta \mu)$ and relative $(\Delta \mu / \mu)$ changes on the free charge carrier density in the presence of the active trap density $n_{\mathrm{tr}}=3 \cdot 10^{11} \mathrm{~cm}^{-3}$ at room temperature $(T=300 \mathrm{~K})$.

the experimental results presented in the work [21]. A slower relative mobility change $\Delta \mu / \mu$ compared to $\Delta \mu$ at larger free charge carrier densities is caused by mobility decreasing with free charge carrier density increasing. Figure 5 shows the relative changes of the conductivity, free charge carrier density, and mobility due to free charge carrier capture.

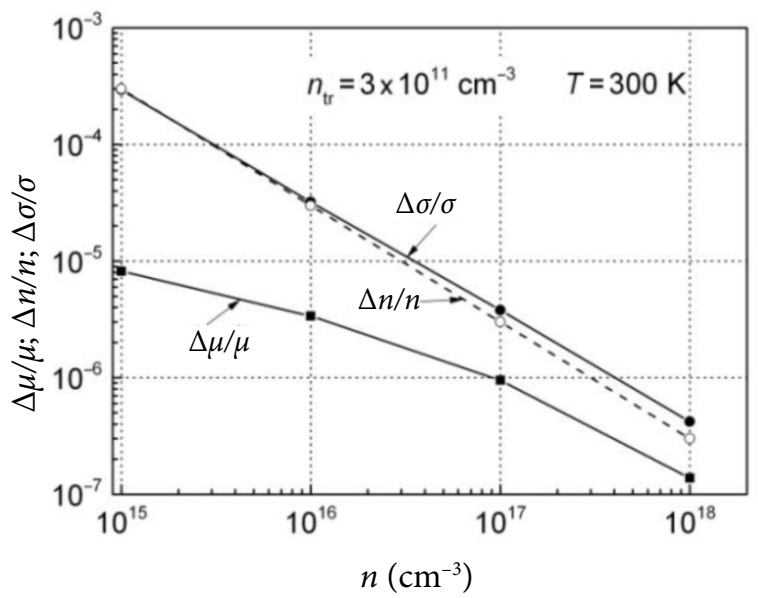

Fig. 5. Comparison of the relative changes of conductivity, charge carrier density and its mobility changes on the free charge carrier densities at the active trap density $n_{\mathrm{tr}}=3 \cdot 10^{11} \mathrm{~cm}^{-3}(T=300 \mathrm{~K})$.

Considering that the relative changes of both the free charge carrier density and mobility due to free charge carrier capture are completely correlated (Eq. (10)), the relative conductivity fluctuations can be presented as

$$
\frac{\Delta \sigma}{\sigma}=\frac{\Delta n}{n}+\frac{\Delta \mu}{\mu}=(1+\beta) \frac{\Delta n}{n}=(1+\beta) \frac{\Delta N}{N},
$$

where the parameter $\beta=(\Delta \mu / \mu) /(\Delta n / n)$ is the contribution of the mobility fluctuations to the total conductivity fluctuations due to charge carrier capture of the free carriers, and $\Delta N / N$ is the relative free charge carrier number changes due to capture of free carriers. For silicon at $n \leq 10^{18} \mathrm{~cm}^{-3}$ the quantity $\beta$ can be expressed as

$$
\beta \approx 0.19 \log \left(1+n /\left(3 \cdot 10^{15}\right)\right)
$$

The dependence of parameter $\beta$ on the free charge carrier density is presented in Fig. 6 .

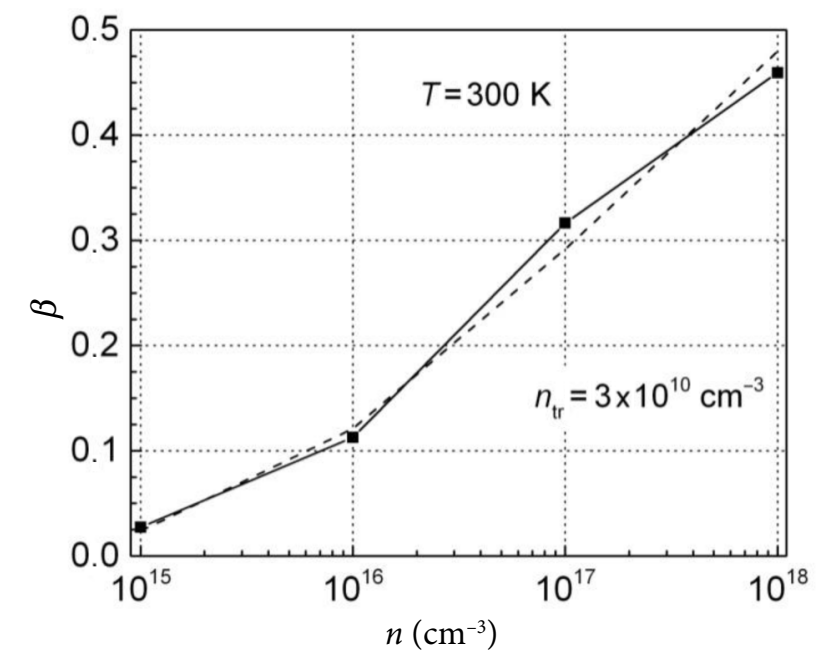

Fig. 6 . The dependence of the parameter $\beta$ on the free charge carrier density (solid dots); the dashed curve is an approximation by Eq. (12).

In papers [15, 16, it has been shown that the expression of the spectral density of the resistance fluctuations caused by free charge carrier number $N$ fluctuations due to the capture-emission process in independent localized capture states (relaxators) can be presented as

$$
\frac{S_{R}(f)}{R^{2}}=\frac{S_{N}(f)}{N^{2}} \approx \frac{0.16 K \delta}{N} \cdot \frac{1}{N f},
$$

where $K \geq 1$ is the average number of relaxators in the sample with arbitrarily distributed relaxation times in every double octave; $\delta$ is the correction factor accounting for the additional resistance changes due to the Debye screening effect. 
Calculation results of the mobility $\mu$ and its change $\Delta \mu$ due to the charge carrier capture in silicon at different free charge carrier densities show that it is necessary to correct the factor $\delta$ in Eq. (13) by accounting for the mobility changes due to the charge carrier capture-emission process. On the basis of these investigations the parameter $\delta$ in Eq. (13) can be corrected as $\delta=(1+\beta)^{2}$. Thus, the low frequency noise level caused by charge carrier capture in localized states of defects in the bulk of homogeneous semiconductors can be described as

$$
\frac{S_{R}(f)}{R^{2}}=\frac{\alpha}{N f} \approx \frac{0.16 K(1+\beta)^{2}}{N} \cdot \frac{1}{N f}
$$

where $\alpha \approx 0.16 \mathrm{~K}(1+\beta)^{2} / N$. Thus, the smaller contribution of the mobility fluctuation to the conductivity fluctuation at $n<10^{16} \mathrm{~cm}^{-3}$ due to the charge carrier trapping process compared to the parameter $\delta$ obtained in [15] can be explained: at these charge carrier densities the mobility is mainly determined by phonon scattering, and the scattering due to negatively charged centres (due to Debye screening) is smaller, as it was pointed out in paper [15] without taking into account the electronphonon scattering.

Table 1. Relation between the empirical parameter $\alpha$ and low-frequency noise description quantities for silicon.

\begin{tabular}{cccc}
\hline$\alpha$ & $10^{-3}$ & $10^{-4}$ & $10^{-5}$ \\
\hline$B$ & 0.11 & 0.11 & 0.11 \\
\hline$K$ & $5 \cdot 10^{4}$ & $5 \cdot 10^{3}$ & $5 \cdot 10^{2}$ \\
\hline$N_{\text {tr }}{ }^{a}$ & $5 \cdot 10^{5}$ & $5 \cdot 10^{4}$ & $5 \cdot 10^{3}$ \\
\hline$N_{\mathrm{A}} / N_{\text {tr }}$ & $1 \cdot 10^{8}$ & $1 \cdot 10^{9}$ & $1 \cdot 10^{10}$ \\
\hline$N / N_{\text {tr }}$ & 20 & 200 & 2000 \\
\hline
\end{tabular}

${ }^{\mathrm{a}} N_{\text {tr }}$ is estimated for the frequency range between $1 \mathrm{~Hz}$ and $1 \mathrm{MHz}$.

In Table 1 , there is a comparison of the $1 / f$ noise description parameters in the frequency range between $1 \mathrm{~Hz}$ and $1 \mathrm{MHz}$ for a silicon sample of $10 \times 10 \times 10 \mu \mathrm{m}=10^{-9} \mathrm{~cm}^{-3}$ with the free charge density $n=10^{16} \mathrm{~cm}^{-3}\left(N=10^{7}\right), N_{\mathrm{tr}}=n_{\mathrm{tr}} V$ (here $V$ is the volume of the sample) and the number of Si atoms $N_{\mathrm{A}}=5 \cdot 10^{13}$ in the sample (density $\left.n_{\mathrm{A}}=5 \cdot 10^{22} \mathrm{~cm}^{-3}\right)$. It is seen that for $\alpha=10^{-3}$ in the pointed frequency range, the average of 1 capture centre for $N_{\mathrm{A}}=10^{8}$ atoms of the sample material is sufficient, and for $\alpha=10^{-5}$ it is only 1 capture centre for $N_{\mathrm{A}}=10^{10}$. These data visibly demonstrate what a high level technology of formation of the samples is necessary in order to obtain samples with small values of parameter $\alpha$.

Thus, it can be stated that the charge carrier capture-emission process not only changes the total number of free charge carriers, but to a certain degree also has an impact on the mobility.

\section{Conclusions}

The carrier mobility dependence on phonon, impurity and carrier-carrier scattering, and other factors have been studied in order to find the mobility fluctuations due to the free charge carrier capture-emission process in homogeneous semiconductors, based on a silicon crystal. It is shown that the charge carrier retrapping process produces the changes of both the total number of free charge carriers in the sample and its mobility. It is also shown that charge carrier density and carrier mobility fluctuations due to the retrapping process are completely correlated, and that their relaxation times are the same as for the charge carrier retrapping process. The expression for evaluation of the active retrapping centre density in the sample from the noise measurements is presented.

The presented Eq. (14) explains not only the $1 / f$ noise level dependence on frequency but also its dependence both on the number of free charge carriers and on the number of capture centres, and the observed proportionality to squared mobility in a particular range of the charge carrier densities.

\section{References}

[1] M.J. Kirton and M.J. Uren, Noise in solid-state microstructures: A new perspective on individual defects, interface states and low-frequency $(1 / f)$ noise, Adv. Phys. 38, 367-468 (1989).

[2] A.L. McWhorter, $1 / f$ noise and germanium surface properties, in: Semiconductor Surface Physics, ed. R.H. Kingston (University of Pennsylvania Press, 1957) pp. 207-228.

[3] M.B. Weissman, $1 / f$ noise and other slow, nonexponential kinetics in condensed matter, Rev. Mod. Phys. 60, 537-571 (1988).

[4] M.S. Kogan, Electronic Noise and Fluctuations in Solids (Cambridge University Press, New York, 1996). 
[5] B. Pelegrini, One model of flicker, burst, and generation-recombination noises, Phys. Rev. B 24, 7071-7083 (1981).

[6] V. Palenskis, Flicker noise problem (review), Lith. J. Phys. 30, 107-152 (1990).

[7] B.K. Jones, Electrical noise as a measure of quality and reliability in electronic devices, Adv. Electron. Electron Phys. 87, 201-257 (1993).

[8] F.N. Hooge, Discussion of resent experiment on 1/f noise, Physica 60, 130-144 (1972)

[9] F.H. Hooge, T.G.M. Kleinpenning, and L.K.J. Vandamme, Experimental studies on $1 / f$ noise, Rep. Progr. Phys. 44, 479-532 (1981).

[10]F.H. Hooge and L.K.J. Vandamme, Lattice scattering causes $1 / f$ noise, Phys. Lett. A 66, 315-316 (1978).

[11]F.N. Hooge, $1 / f$ noise sources, IEEE Trans. Electron Devices 41, 1926-1935 (1994).

[12]L.K.J. Vandamme and F.H. Hooge, What do we certainly know about $1 / f$ noise in MOSTs? IEEE Trans. Electron Devices 55, 3070-3085 (2008).

[13]F.H. Hooge, $1 / f$ noise in semiconductors. Has anything been proved experimentally? In: Proceedings of the 7th Vilnius Conference on Fluctuation Phenomena in Physical Systems, ed. by V. Palenskis (VU Press, Vilnius, 1994) pp. 61-69.

[14]F.H. Hooge, $1 / f$ noise in semiconductor materials, in: Proceedings of the 13th International Conference on Noise in Physical Systems and $1 / f$
Fluctuations, eds. V. Bareikis and R. Katilius (World Scientific, Singapore, 1995) pp. 8-13.

[15]V. Palenskis and K. Maknys, Nature of low-frequency noise in homogeneous semiconductors, Sci. Rept. 5, 18305 (2015).

[16]V. Palenskis, The charge carrier capture-emission process - the main source of the low-frequency noise inhomogeneous semiconductors, Lith. J. Phys. 56, 200-206 (2016).

[17]G. Masetti, M. Severi, and S. Solmi, Modeling of carrier mobility against carrier concentration in arsenic-, phosphorus-, and boron-doped silicon, IEEE Trans. Electron Devices 30(7), 764-769 (1983).

[18]A. Schenk, Advanced Physical Models for Silicon Device Simulation (Springer, Wien, 1998).

[19]C. Canali, G. Majni, R. Minder, and G. Ottaviani, Electron and hole drift velocity measurements in silicon and their empirical relation to electric field and temperature, IEEE Trans. Electron Devices 22(11), 1045-1047 (1975).

[20]D.B.M. Klaassen, J.W. Slotboom, and H.C. de Graaff, Unified apparent bandgap narrowing in $n$ and $p$-type silicon, Solid State Electron. 35(2), 125-129 (1992).

[21]C. Jacoboni, C. Canali, G. Ottaviani, and A. Alberigi Quaranta, A review of some charge transport properties of silicon, Solid State Electron. 20, 77-89 (1977).

\title{
KRŪVININKŲ JUDRIO FLIUKTUACIJOS DĖL KRŪVININKŲ PAGAVIMO
}

\author{
V. Palenskis, J. Vyšniauskas, J. Glemža, J. Matukas \\ Vilniaus universiteto Taikomosios elektrodinamikos ir telekomunikaciju institutas, Vilnius, Lietuva
}

\section{Santrauka}

Naudojant Synopsis TCAD Sentaurus programą, apskaičiuotos krūvininkų judrio fliuktuacijos silicio kristale dèl krūvininkų pagavimo lokalizuotomis defektų būsenomis, atsižvelgiant ị judrio priklausomybę nuo sklaidos gardelès virpesiais ir krūvininkų abipusès sklaidos, taip pat atsižvelgta ị judrio priklausomybę nuo elektrinio lauko stiprio ir draudžiamosios energijos tarpo kitimo dèl krūvininkų tankio.
Parodyta, kad dèl laisvųjų krūvininkų pagavimo susikuria net tik laisvųjų krūvininkų tankio, bet ir jų judrio fliuktuacijos. Šios fliuktuacijos yra visiškai koreliuotos, o jų relaksacijos trukmé lygi pagavimo reiškinio relaksacijos trukmei. Pateikta išraiška, kaip ịvertinti pagavimo centrų tanki pagal žemadažnio triukšmo galios spektrinị tankị. 